\title{
A Prediction Method of Tensile Young's Modulus of Concrete at Early Age
}

\author{
Isamu Yoshitake, ${ }^{1}$ Farshad Rajabipour, ${ }^{2}$ Yoichi Mimura, ${ }^{3}$ and Andrew Scanlon ${ }^{2}$ \\ ${ }^{1}$ Department of Civil and Environmental Engineering, Yamaguchi University, Ube, Yamaguchi 755-8611, Japan \\ ${ }^{2}$ Department of Civil and Environmental Engineering, Pennsylvania State University, University Park, PA 16802, USA \\ ${ }^{3}$ Department of Civil and Environmental Engineering, Kure National College of Technology, Kure, Hiroshima 737-8506, Japan
}

Correspondence should be addressed to Isamu Yoshitake, yositake@yamaguchi-u.ac.jp

Received 7 March 2011; Accepted 22 September 2011

Academic Editor: Kent A. Harries

Copyright (C) 2012 Isamu Yoshitake et al. This is an open access article distributed under the Creative Commons Attribution License, which permits unrestricted use, distribution, and reproduction in any medium, provided the original work is properly cited.

Knowledge of the tensile Young's modulus of concrete at early ages is important for estimating the risk of cracking due to restrained shrinkage and thermal contraction. However, most often, the tensile modulus is considered equal to the compressive modulus and is estimated empirically based on the measurements of compressive strength. To evaluate the validity of this approach, the tensile Young's moduli of 6 concrete and mortar mixtures are measured using a direct tension test. The results show that the tensile moduli are approximately 1.0-1.3-times larger than the compressive moduli within the material's first week of age. To enable a direct estimation of the tensile modulus of concrete, a simple three-phase composite model is developed based on random distributions of coarse aggregate, mortar, and air void phases. The model predictions show good agreement with experimental measurements of tensile modulus at early age.

\section{Introduction}

An accurate estimation of the Young's modulus is important for proper structural design of concrete members, and ensuring their serviceability, such as controlling deflections and crack widths. In particular, the time-dependent development of the tensile Young's modulus at early ages is needed for estimation of the tensile stresses that are generated due to restrained thermal and hygral shrinkage. These tensile stresses may lead to premature cracking of concrete members. Currently, the tensile modulus is assumed to be equal in value to the compressive modulus and is estimated using empirical correlations based on the compressive strength of concrete [1, 2]. The Architectural Institute of Japan (AIJ) [3] points out that employing the tensile modulus is more appropriate for estimation of the risk of earlyage cracking; however, the specification indicates that the compressive modulus may be used instead of the tensile modulus because investigations dealing with the tensile modulus are currently insufficient. Since the tensile behavior of concrete is more significantly affected by the presence of flaws (e.g., microcracks or large capillary pores common in early-age concrete), it is important to develop tools to predict or measure the tensile properties more accurately.

Direct tension tests have been conducted in earlier studies to investigate the tensile strength and the tensile strain capacity of concrete. Although the tensile moduli can be obtained from the linear portion of the stress-strain diagram in these reports, the focus of these earlier studies has been primarily on mature concrete. As such, little information is available on the early-age (i.e., less than 28 days) tensile modulus and its development with time. In addition, a reliable model to aid design engineers in estimating the tensile modulus based on concrete's proportions and age does not currently exist.

Xie and Liu [4] conducted a direct tension test using small and large specimens of mature concrete with various aggregate sizes, and measured the tensile strength, strain capacity, and Young's modulus. They observed that increasing the maximum aggregate size does not have a proportional impact on tensile strength and tensile modulus of concrete. Oluokun et al. [5] researched the compressive 
Young's modulus and Poisson's ratio of early-age concrete. They concluded that the compressive modulus is proportional to the 0.5 power of the compressive strength, and the ACI 318 formula for estimation of the compressive modulus is valid after the age of 12 hours. Hagihara et al. [6] investigated the tensile creep of high-strength concrete at early age, and reported that the tensile Young's moduli are approximately $15 \%$ higher than the compressive moduli. This is an important conclusion and should be evaluated for other concretes with normal strength. Swaddiwudhipong et al. [7] investigated the mechanical properties of concrete containing ground granulated blast furnace slag and pulverized fuel ash. They reported that the tensile moduli of all concretes tested had correlated well with the tensile strength; although no predictive formula is presented for the tensile modulus. Aoki et al. [2] also conducted direct tension test in order to obtain tensile strength and Young's modulus of mature concrete and found that the tensile modulus is $9-12 \%$ higher than the compressive modulus for these concretes. Bissonnette et al. [8] researched the tensile creep of concrete at early age, and presented some measurements of the tensile Young's modulus at the age of 7 and 28 days. In an earlier work [9], the authors investigated the tensile Young's moduli by using a direct tension test, and presented a composite model derived from the Hirsh model [10] to predict the tensile modulus. The model showed good agreement with the experimental data as well as other composite models offered by Counto [11] and Hashin [12]. Recently, Mihashi and Leite [13] presented a stateof-the-art report on early age cracking of concrete and its mitigation techniques that includes some information on the mechanical properties of concrete at early ages.

As described above, the investigations focusing on the tensile Young's modulus of early-age concrete are few, and more experimental data will be needed to establish reliable predictive correlations for estimation of the tensile modulus. The present paper reports laboratory measurements of the tensile modulus within the first 7 days of hydration. Three concrete mixtures (with different $W / C$ ) were tested. In addition, to evaluate the effect of aggregate size, duplicate concrete mixtures were prepared and sieved before setting using a $5 \mathrm{~mm}$ mesh sieve. The resulting mortars were tested to determine their tensile Young's modulus. Using the measurements results, a composite model was developed and calibrated which can serve as a simple method for estimating the tensile Young's modulus of concrete.

\section{Experimental Program}

2.1. Materials and Mix Proportions of Concrete. This study employed ordinary Portland cement with a density of $3.14 \mathrm{~g} / \mathrm{cm}^{3}$. Tables 1 and 2 provide the details of the cement and aggregate used. Proportions of the six concrete and mortar mixtures tested in this study are given in Table 3. The proportions of the concrete were designed by referring to mixture proportions used in a ready mixed concrete plant in Japan. Mortars were obtained by sieving plastic concrete mixtures as discussed above. This was done to duplicate the mechanical properties (i.e., tensile modulus)
TABle 1: Physical and chemical compositions of cement.

\begin{tabular}{lc}
\hline & Ordinary Portland cement \\
\hline Density & $3.14 \mathrm{~g} / \mathrm{cm}^{3}$ \\
Blaine fineness & $3340 \mathrm{~cm}^{2} / \mathrm{g}$ \\
Setting time start-end & $2 \mathrm{~h} 26 \mathrm{~m}-3 \mathrm{~h} 34 \mathrm{~m}$ \\
Comp. strength at 3 days & $30.8 \mathrm{MPa}$ \\
at 7 days & $46.3 \mathrm{MPa}$ \\
at 28 days & $63.6 \mathrm{MPa}$ \\
$\mathrm{Chemical}$ compositions & \\
$\mathrm{CaO}$ & $64.5 \%$ \\
$\mathrm{SiO}_{2}$ & $20.5 \%$ \\
$\mathrm{Al}_{2} \mathrm{O}_{3}$ & $5.7 \%$ \\
$\mathrm{Fe}_{2} \mathrm{O}_{3}$ & $2.9 \%$ \\
$\mathrm{MgO}$ & $1.27 \%$ \\
$\mathrm{SO}_{3}$ & $2.15 \%$ \\
$\mathrm{Cl}^{-}$ & $0.009 \%$ \\
Loss of ignition & $1.89 \%$ \\
\hline
\end{tabular}

TABLe 2: Properties of aggregate.

\begin{tabular}{lcc}
\hline & Fine agg. $S$ & Crushed rock $G$ \\
\hline Materials & Sea sand & Andesite \\
Density & $2.56 \mathrm{~g} / \mathrm{cm}^{3}$ & $2.73 \mathrm{~g} / \mathrm{cm}^{3}$ \\
Fineness modulus & 3.36 & 6.66 \\
Absorption & $1.3 \%$ & $1.3 \%$ \\
Size (max. - min.) & $5 \mathrm{~mm}$ & $20-5 \mathrm{~mm}$ \\
\hline
\end{tabular}

of the mortar portion of the concretes as closely as possible. These results are needed to develop the composite model as discussed in Section 3. In all mixtures, proper dosages of air entraining and water reducing admixtures were used to ensure consistency and workability of the concrete (Table 3 ).

2.2. Test Methods and Specimens. Figure 1 shows the direct tension apparatus used in this study. Figure 2 shows the geometry of the dog-bone specimens tested. To reduce bending moment during test, the ends of the dog-bone specimens were not fully fixed but were allowed rotational freedom. The direct tension apparatus manually provides a tensile force to a specimen using a lever. Overall, an approximately constant strain rate of 2 to $3 \times 10^{-6} / \mathrm{sec}$ was applied. To measure tensile strain of specimens, an embedded strain sensor was used which includes an electrical resistance wire strain gage of $60 \mathrm{~mm}$ long coated by epoxy resin with tensile modulus of $2.8 \mathrm{kPa}$ as shown in Figure 2. The overall sensor size was $120 \times 10 \times 3 \mathrm{~mm}$; as such the area ratio of the sensor to concrete was smaller than $1.4 \%$ to ensure that the sensor has little influence on the behavior of specimens when subjected to tensile force. While this setup was used to measure the tensile modulus, it may not be suitable for measurement of the tensile strength since a number of breaks occurred within the end zones of the dogbone specimens (Figure 3). 
TABLE 3: Mixture proportions of concrete.

\begin{tabular}{|c|c|c|c|c|c|c|c|}
\hline ID & $W / C(\%)$ & Water $\left(\mathrm{kg} / \mathrm{m}^{3}\right)$ & Cement $\left(\mathrm{kg} / \mathrm{m}^{3}\right)$ & $S\left(\mathrm{~kg} / \mathrm{m}^{3}\right)$ & $G\left(\mathrm{~kg} / \mathrm{m}^{3}\right)$ & WRA $\left(\mathrm{kg} / \mathrm{m}^{3}\right)$ & Air (\%) \\
\hline O57 & 57 & 165 & 290 & 812 & 1030 & 2.9 & 4.5 \\
\hline $\mathrm{O} 57 \mathrm{~m}^{\# 1}$ & 57 & 265 & 466 & 1304 & - & 4.7 & - ${ }^{\# 2}$ \\
\hline O39 & 39 & 169 & 434 & 790 & 933 & 4.3 & 3.8 \\
\hline $\mathrm{O} 39 \mathrm{~m}^{\# 1}$ & 39 & 257 & 659 & 1200 & - & 6.5 & - $^{* 2}$ \\
\hline $\mathrm{O} 25$ & 25 & 170 & 680 & 694 & 818 & 6.8 & 3.6 \\
\hline $\mathrm{O} 25 \mathrm{~m}^{\# 1}$ & 25 & 243 & 971 & 991 & - & 9.7 & — ${ }^{2}$ \\
\hline
\end{tabular}

${ }^{\# 1}$ Mortar is made from wet screening of concrete (maximum mesh size: $5 \mathrm{~mm}$ ).

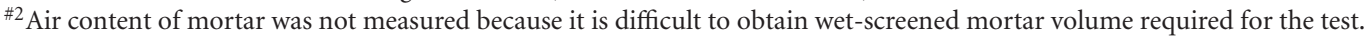

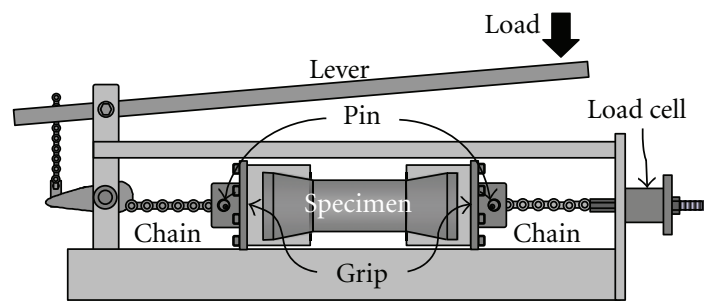

Figure 1: Direct tension test using a dog-bone-shaped specimen.

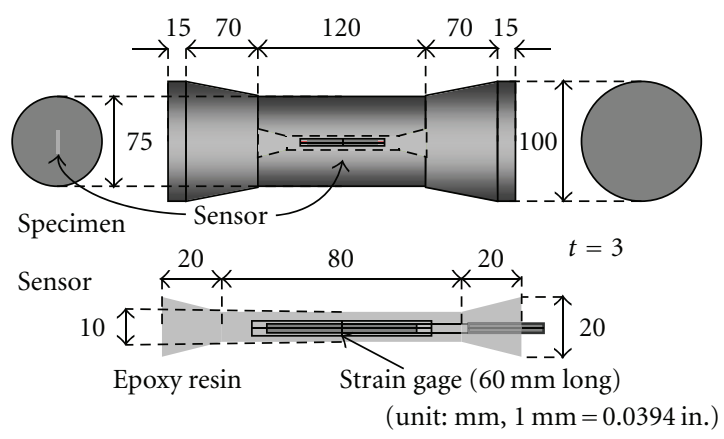

FIgURE 2: A dog-bone-shaped specimen and an embedded sensor.

\section{Prediction of the Young's Modulus Using a Composite Model}

In addition to the tensile modulus, the compression and indirect tension tests were conducted using cylindrical specimens. The compressive modulus of concrete was obtained using an extensometer equipped with 2 displacement gages, and the modulus of mortar was measured using 2 wire strain gages $30 \mathrm{~mm}$ long. The cylindrical specimens (diameter $\times$ height) tested were $100 \times 200 \mathrm{~mm}$ for concrete, and $50 \times$ $100 \mathrm{~mm}$ for mortar. Three cylindrical specimens were used for each test per each mixture, and the average of the three measurements was used. The tests were performed at ages 1 , 2, 3, and 7 days.

3.1. Determination of the Tensile Young's Modulus. To measure the tensile modulus, the tensile force is applied to the specimen at strain intervals of $10 \times 10^{-6}$. In order to prevent failure of specimen, the maximum strain during the test is set at $60 \times 10^{-6}$. Since the plastic strain of concrete at early age

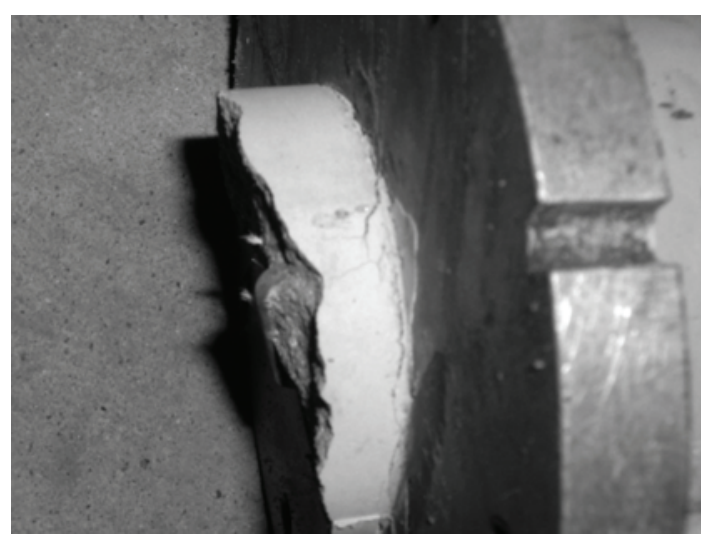

FIGURE 3: Typical failure within the end zone of the dog-boneshaped specimen.

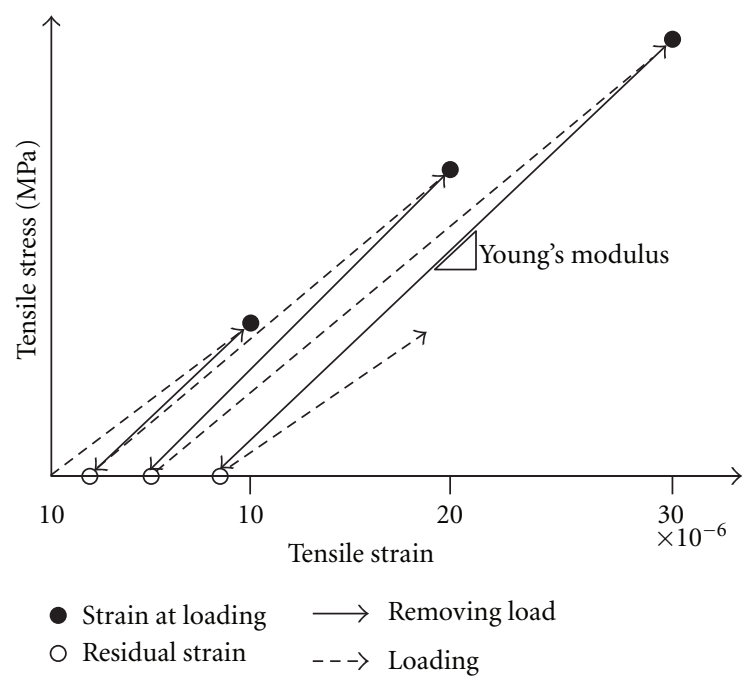

FIGURE 4: Evaluation method for tensile Young's modulus.

may comprise a high percentage of the total strain measured, the tensile modulus is obtained from the unloading branches of the stress-strain relation as shown in Figure 4. The slope of the unloading branches after the specimen was loaded to $10 \times 10^{-6}, 20 \times 10^{-6}$, and so forth, is determined and averaged to obtain the tensile modulus of the specimen. The force is measured twice at each strain level using a load cell 


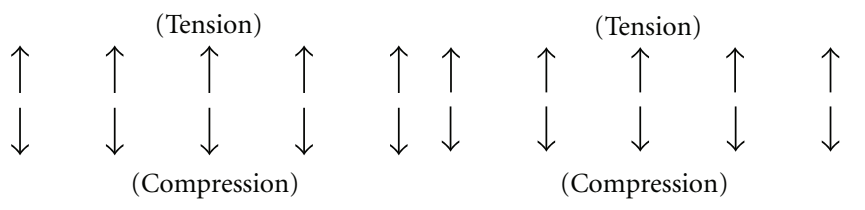

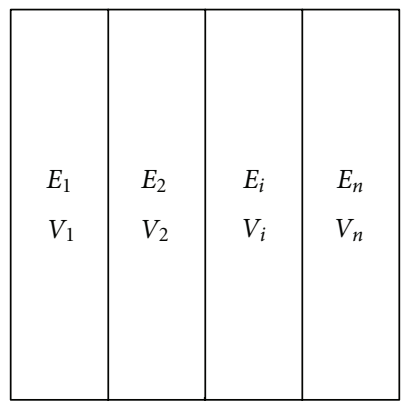

(Compression)

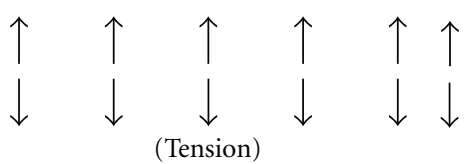

(a)

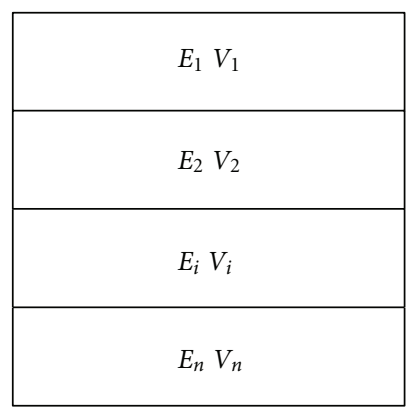

(Compression)

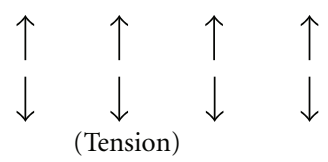

(b)
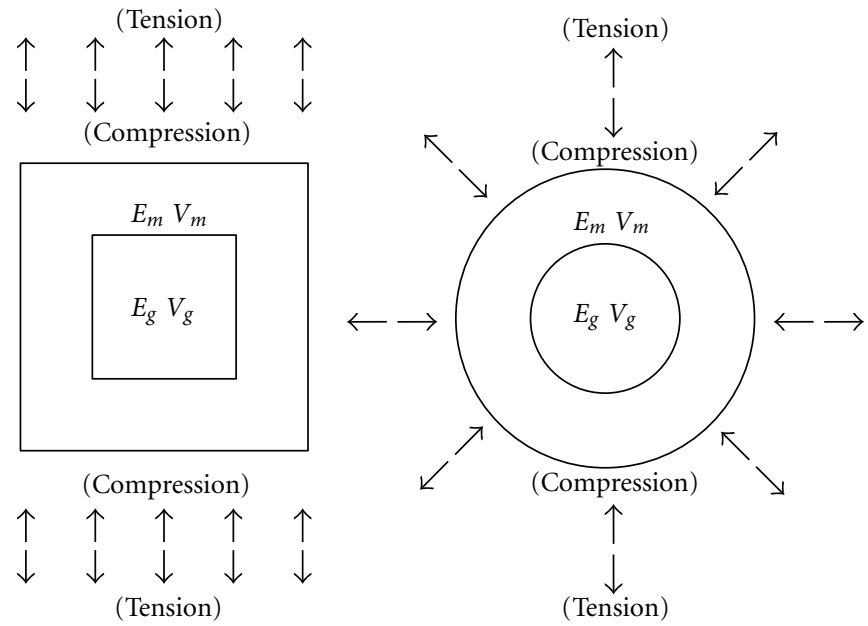

(c)

(d)

Figure 5: Typical composite models for predicting Young's modulus: (a) Parallel model, (b) Series model, (c) Counto model, and (d) Hashin model.

with an accuracy of $0.1 \mathrm{kN}$ and capacity of $200 \mathrm{kN}$. As will be discussed later, the maximum residual strain after unloading of each specimen was measured as $3 \times 10^{-6}$. In each case, concrete and mortar specimens were made from the same batch using the sieving procedure mentioned above.

As mentioned earlier, the tensile Young's modulus of concrete is often assumed to be equal in value to the compressive modulus. In addition, the compressive modulus of concrete is frequently estimated based on empirical correlations with concrete compressive strength. The compressive modulus of concrete has also been related to the volume and mechanical properties of concrete's constituents (aggregates, paste, etc.) using some classical composite models such as those presented by Zhou et al. [14], Topçu [15], and
Yoshitake et al. [9]. A brief overview of these models is provided below.

The typical composite models for estimation of the elastic modulus are illustrated in Figure 5. These include (a) the Parallel model, (b) the Series model, (c) the Counto model [11], and (d) the Hashin model [12]; as represented by the following:

$$
\begin{gathered}
\text { Parallel model: } E=\sum_{i=1}^{n} E_{i} \cdot V_{i}, \\
\text { Series model: } \frac{1}{E}=\sum_{i=1}^{n} \frac{V_{i}}{E_{i}},
\end{gathered}
$$




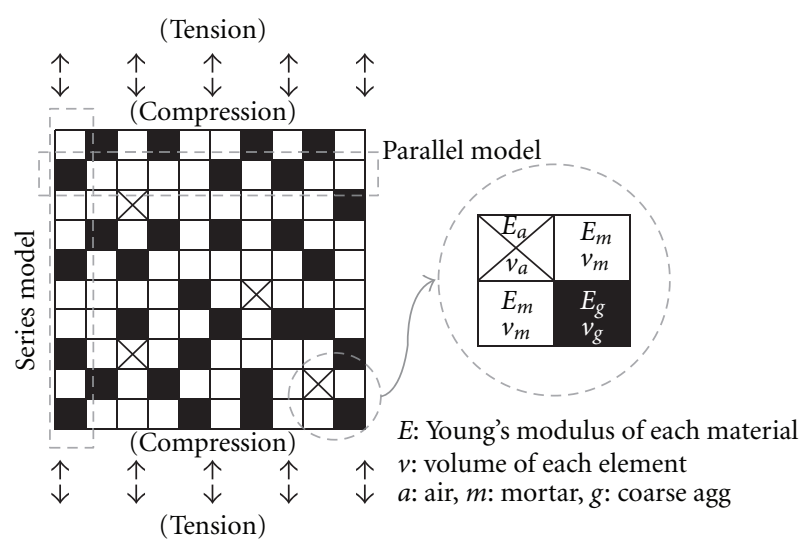

Figure 6: An example of a simple composite model using parallel and series models.

$$
\begin{gathered}
\text { Counto model: } \frac{E}{E_{m}}=1+\frac{V_{g}}{\sqrt{V_{g}}-V_{g}+E_{m} /\left(E_{g}-E_{m}\right)}, \\
\text { Hashin model: } \frac{E}{E_{m}}=\frac{V_{m} E_{m}+\left(1+V_{g}\right) E_{g}}{\left(1+V_{g}\right) E_{m}+V_{m} E_{g}},
\end{gathered}
$$

where $E_{i}$ and $V_{i}$ represent the Young's modulus and the volume fraction of concrete constituents (e.g., mortar, coarse aggregate, etc.), $n$ is the number of constituents, and the subscripts $m$ and $g$ refer to mortar and coarse aggregate, respectively. The Counto and Hashin models are based on a 2-phase composite (mortar and aggregate). While these models are generally more accurate than simple parallel and series models, they may estimate the Young's modulus inappropriately for concretes containing high aggregate volumes or high air content.

In the present work a new triphase model is proposed based on random distribution of elements within a 2dimensional $80 \times 80$ grid (Figure 6). Each element in the model is composed of mortar, coarse aggregate, or air. The number elements corresponding to each phase is proportional to the volume fraction of that phase in concrete. Elements are placed randomly in the model using a Monte Carlo procedure. To determine the tensile modulus of the grid, simple micromechanical calculations are performed based on the series and parallel models. First the tensile modulus of each row of elements is determined using the parallel model and then the modulus of the grid is determined by combining all rows using the series model. Alternatively, the modulus of each column can first be determined using the series model and then the columns are combined using the parallel model.

\section{Experimental Results and Discussion}

4.1. Evaluation of the Reliability of the Embedded Strain Sensor. It is important to ensure proper measurements of the tensile strain using the embedded strain sensor. For this purpose, a dog-bone concrete specimen is tested in tension

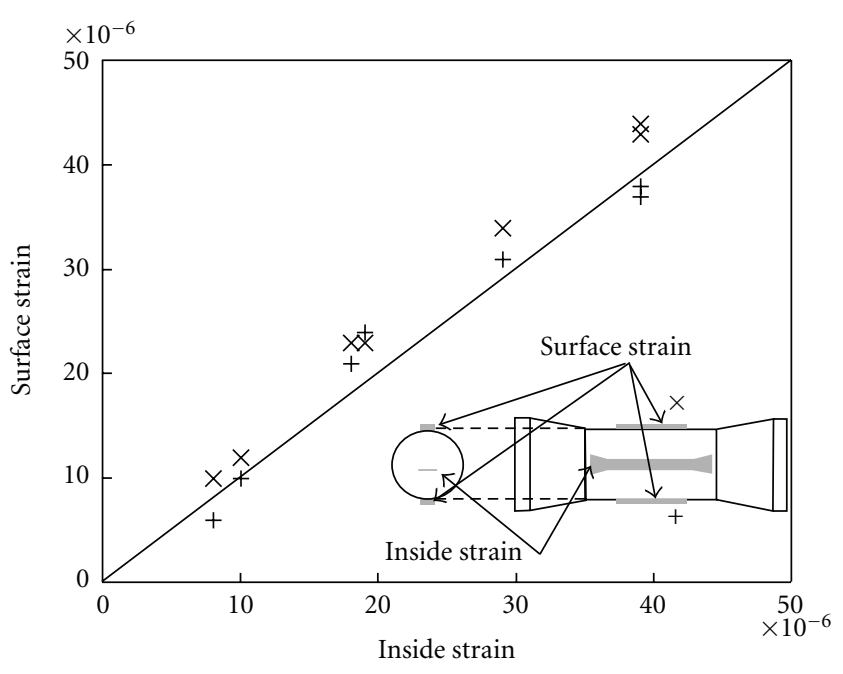

Figure 7: Comparison of inside strain and surface strain.

and the tensile strain is measured by both the embedded gage as well as 2 wire strain gages mounted on the surface of the concrete specimen. Figure 7 presents the results showing that the internally measured strain is practically equal to the surface measured strains. This implies that the tensile stress is applied uniformly to the specimen and the embedded sensor can be used to monitor concrete's tensile strain. Based on this conclusion, further measurements in this study employ only the embedded sensor.

4.2. Tensile Stress-Strain Responses. Figure 8 presents examples of the tensile stress-strain responses of each concrete. As shown, the slope of each stress-strain regression line (i.e., the tensile modulus) develops with increasing age and reducing the water-cement ratio $(W / C)$ of concrete. Figure $8(a)$ shows the stress-strain response at 1 day; the results indicate that the residual strain after unloading of specimens is zero (i.e., plastic strain at age of 1 day when specimen are loaded to $60 \times 10^{-6}$ is negligible). Note that the response of mixture $\mathrm{O} 57(W / C=57 \%)$ at 1 day could not be obtained because the concrete was too weak to allow performing the direct tension test. Figure 8(b) presents the stress-strain responses at 7 days; the maximum residual strain after loading specimens to $60 \times$ $10^{-6}$ is $3 \times 10^{-6}$ corresponding to the mixture O39. For this mix, had the loading branches of the stress-strain response been used to determine the modulus, the tensile modulus would be estimated as $31.2 \mathrm{GPa}$, comparing with $33.0 \mathrm{GPa}$ obtained from using the unloading stress-strain branches. The ratio of the modulus obtained by the two methods is approximately 0.95 .

4.3. Time Dependent Development of the Mechanical Properties. The results of the compressive and splitting tensile strength measurements of the three concrete mixtures are presented in Figure 9. At 7 days, the concrete mixtures have compressive strengths in the range of 20 to $45 \mathrm{MPa}$, and splitting tensile strengths in the range of 2 to $3.3 \mathrm{MPa}$. The time-dependent compressive and tensile Young's moduli are 


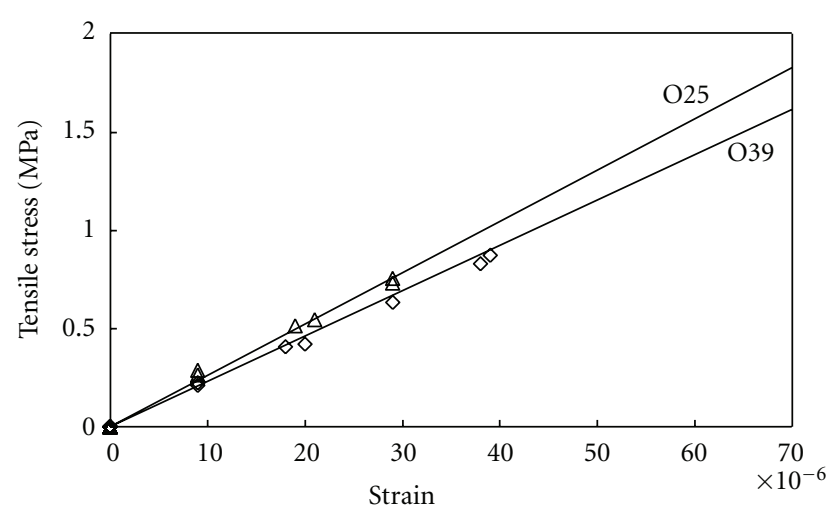

$\diamond \mathrm{O} 39$

$\triangle \mathrm{O} 25$

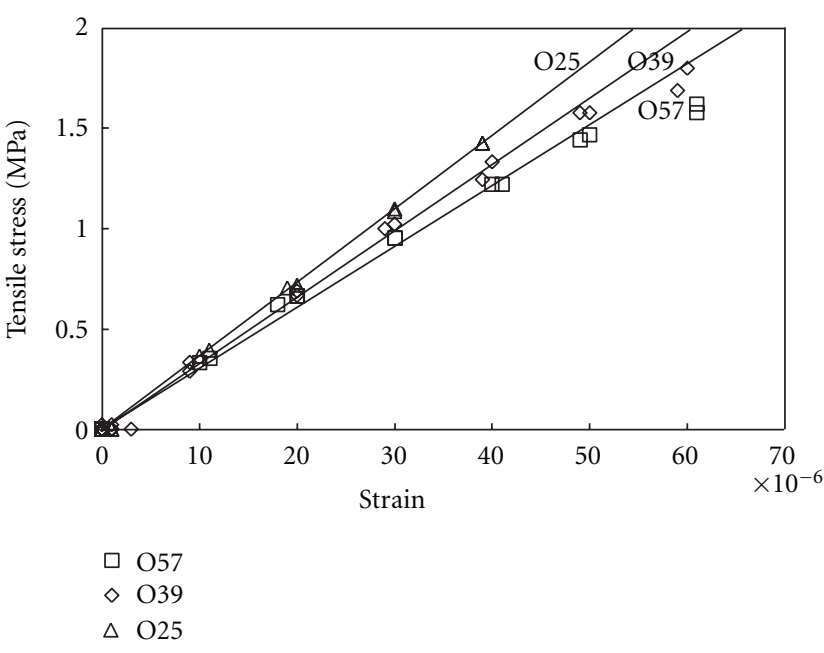

(b)

Figure 8: Tensile stress-strain responses: (a) age of 1 day and (b) age of 7 days.

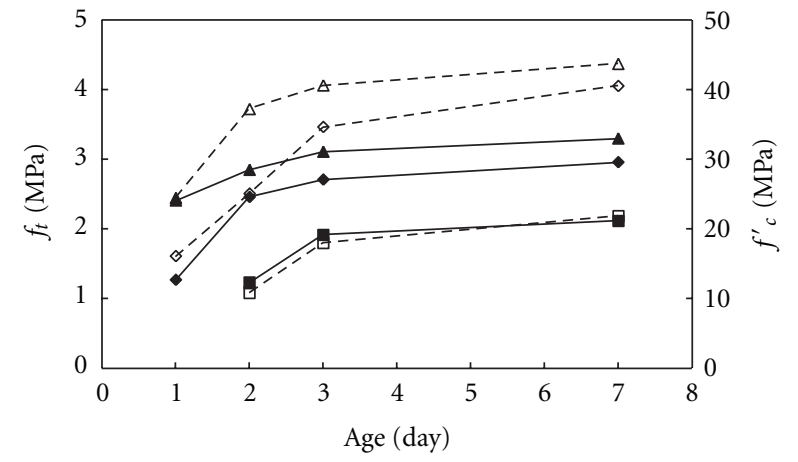

$\begin{array}{ll}-\bullet-\text { O57, compressive } & \rightarrow \text { O57, tensile } \\ -\diamond-\text { O39, compressive } & \rightarrow \text { O39, tensile } \\ -\triangle-\text { O25, compressive } & \rightarrow \text { O25, tensile }\end{array}$

FIGURE 9: Strengths versus age of concrete.

presented in Figure 10. The compressive moduli in the graph demonstrate the secant moduli under $33 \%$ of the maximum stress. Based on Figure 10, the tensile Young's moduli are approximately $1.0-1.3$-times larger than the compressive moduli. The result may be caused by different response to stress applied to each specimen, such that the tensile stresses were less than $10 \%$ of the compressive stresses. This difference can be especially significant at early ages when the large macropores dictate the tensile response of concrete.

A comparison between the tensile modulus of concrete and the corresponding mortar specimens are provided in Figure 11. The results indicate that the concrete tensile modulus is always higher than the mortar modulus due to the stiffness provided by the coarse aggregates in concrete. However, the difference is narrowed as concrete ages due to hydration of cement which results in an increased stiffness of the mortar.

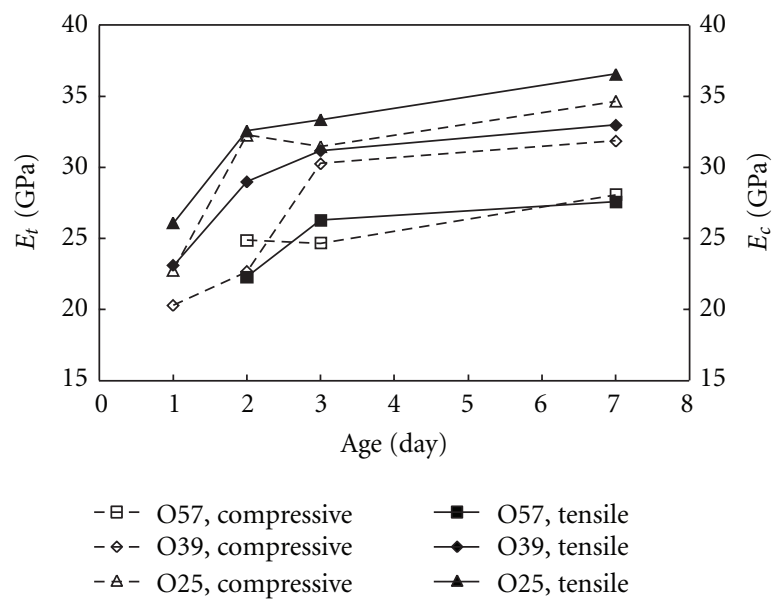

Figure 10: Young's moduli versus age of concrete.

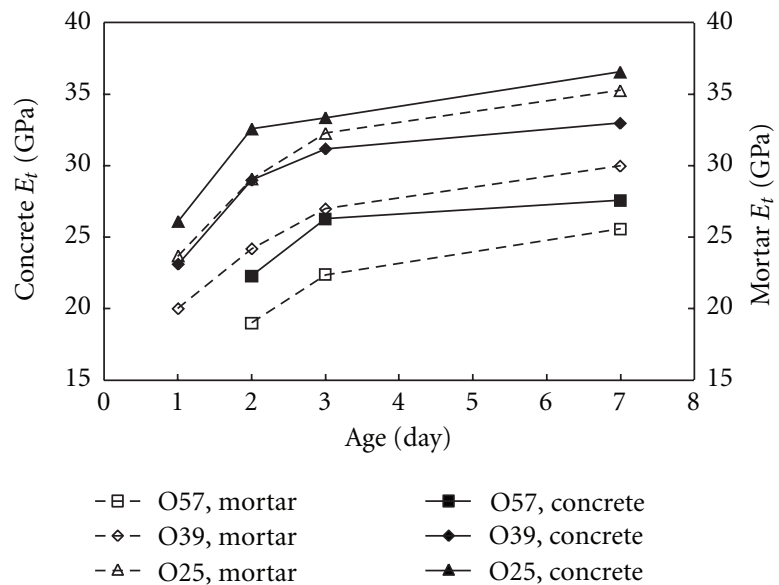

Figure 11: Tensile Young's modulus predicted by employing grids of different fineness. 


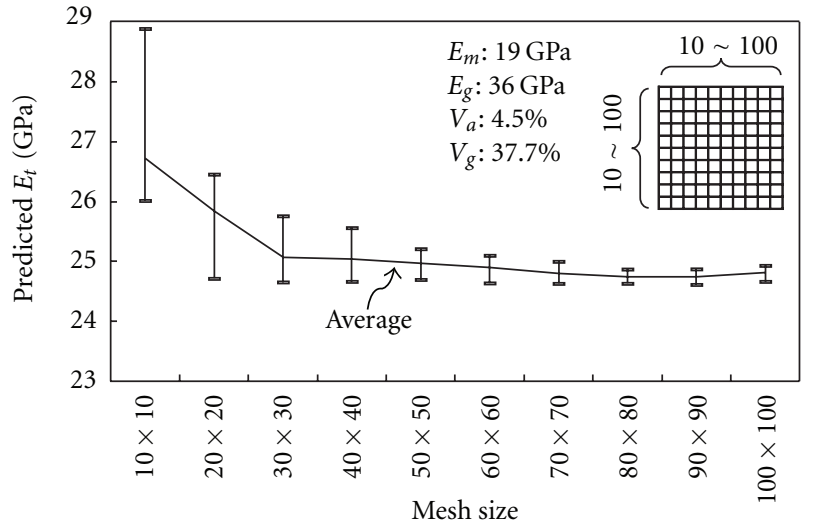

Figure 12: Comparison of experiment and predicted tensile Young's modulus.

\section{Prediction of the Tensile Young's Modulus at Early Age}

5.1. Input Data for Development of the Simplified Composite Model. The tensile Young's moduli of coarse aggregates and mortar are needed as input parameters for use in the composite models. While the moduli of mortar is directly measured (Figure 11), it is difficult to directly obtain the tensile modulus of the aggregate due the size and number of specimens required for tensile testing, difficulty in using a proper tensile grip method of the rock specimen, as well as the variability in the material properties due to layering and impurities of the rock. Thus, the tensile Young's modulus of the coarse aggregate is indirectly calculated by employing the Counto and Hashin models in the present study. The study estimates the tensile Young's modulus $\left(E_{g}\right)$ of $36.0 \mathrm{GPa}$ from the experimental result of $\mathrm{O} 25$ at age of 7 days, for which the modulus of mortar was almost equal to the modulus of concrete. That is, the estimated value to the modulus is little affected by the models used for obtaining the modulus of the aggregate. Similar values are obtained based on testing O25 at earlier ages or by testing the other two mixtures.

Table 4 provides the input data for the composite model. The volume fractions of each component (mortar, coarse aggregates, and air) are obtained from the mix proportions given in Table 3. To determine the appropriate number of elements in the model, the study estimates the tensile Young's moduli of concrete by employing models of various mesh sizes. Figure 12 presents the resulting tensile moduli predicted as a function of mesh fineness. The graph shows the maximum, minimum, and average moduli obtained from 10 consecutive simulations in each model. Based on these results, a $80 \times 80$ model was chosen for the remaining simulations in this work.

5.2. Quality of the Model Predictions. Figure 13 shows the tensile Young's moduli of all concrete specimens predicted by using the proposed composite model. Each bar presents the average of 10 simulations for each concrete mixture and at each age. The bar graph indicates that the predicted

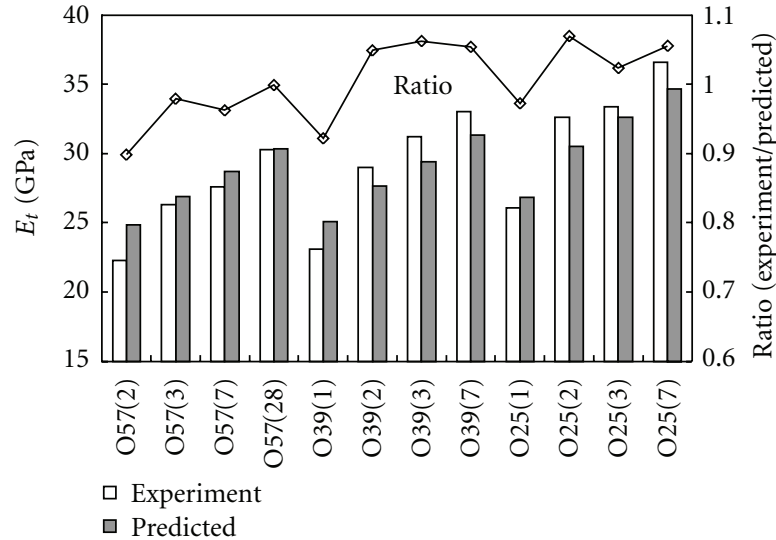

FIGURE 13: Tensile Young's modulus predicted by employing grids of different fineness.

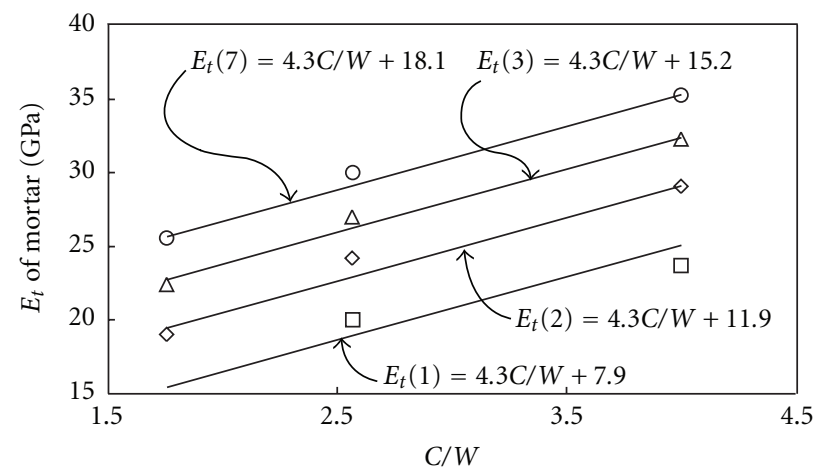

FIGURE 14: Relations between cement-water ratio and tensile Young's moduli of mortar.

Young's moduli are in good agreement with the experimental values; the ratio of the two is in range of 0.90 to 1.07. This implies that the tensile modulus of concrete can be predicted appropriately by employing the composite model when the volume fraction of constituents is known.

5.3. Empirical Formula for the Tensile Modulus of Mortars in This Study. Considering that the Young's modulus of coarse aggregate and air content of concrete are ageindependent, the Young's modulus of concrete at early age may be predicted if the modulus of mortar can be estimated appropriately. For the mortar studied in this work, empirical correlations between the experimental measurement modulus, the $W / C$, and the age of mortars are established as presented in Figure 14. The figure shows a linear correlation between the inverse water to cement ratio $(C / W)$ and the tensile moduli of mortar $\left(E_{t}\right)$ at ages of $1,2,3$, and 7 days. Interestingly, the slope $k_{i}$ of all regression lines in the graph is approximately $4.3 \mathrm{GPa}$ :

$$
\text { Relation of } E_{t}-\frac{C}{W}: E_{t}=k_{i} \cdot \frac{C}{W}+C_{i},
$$

where $E_{t}(\mathrm{GPa})$ is the tensile modulus of mortar, and $C_{i}$ $(\mathrm{GPa})$ is an age-dependent parameter in each regression line. 
TABLE 4: Input data for the composite model.

\begin{tabular}{lcccccccc}
\hline \multirow{2}{*}{ Mix. ID } & \multirow{2}{*}{$V_{m}$} & \multirow{2}{*}{$V_{g}$} & $V_{a}$ & \multicolumn{5}{c}{$E_{t}$ of mortar $(\mathrm{GPa})$ shown in Figure 11} \\
& & & & & 1 day & 2 days & 3 days & $E_{g}(\mathrm{GPa})$ \\
\hline O57 & $57.7 \%$ & $37.7 \%$ & $4.5 \%$ & N/A & 19.0 & 22.4 & 25.6 & 36.0 \\
O39 & $62.0 \%$ & $34.2 \%$ & $3.8 \%$ & 20.0 & 24.2 & 27.0 & 30.0 & 36.0 \\
O25 & $66.4 \%$ & $30.0 \%$ & $3.6 \%$ & 23.7 & 29.1 & 32.3 & 35.3 & 36.0 \\
\hline
\end{tabular}

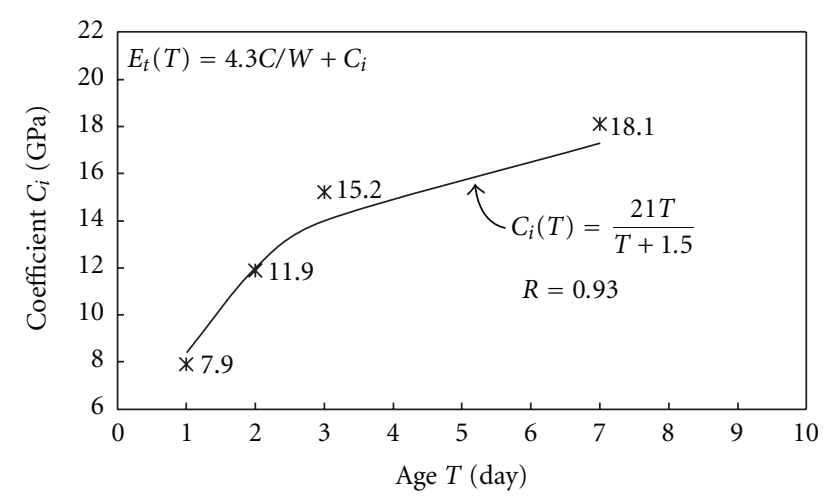

Figure 15: Coefficient $C_{i}$ of the regression line versus age of mortar.

The change in $C_{i}$ with age of mortar is shown in Figure 15. A Goral curve [16], which is often used for estimating concrete strength development with age, is fit to the data points resulting in the following:

$$
\text { Coefficient } C_{i} \text { with age: } C_{i}=\frac{21 T}{T+1.5},
$$

where $T$ is mortar age in days. Combining (5) and (6) results in

Tensile Young's modulus of mortar:

$$
E_{t}(T)=4.3 \frac{C}{W}+\frac{21 T}{T+1.5},
$$

where $E_{t}$ is the estimated tensile Young's modulus of mortar (GPa).

It must be noted that similar to modulus of concrete, the tensile modulus of mortar is a function of the volume fraction and stiffness of sand, volume fraction and modulus of cement paste (itself a function of age and $W / C$ ), and the air content of the mortar. By accounting for age and $W / C$, (7) can provide an estimate for the tensile modulus of mortars with similar volume fraction and stiffness of the fine aggregates. Young's modulus of coarse aggregate can be considered as an influencing factor to the tensile modulus of concrete, so this equation including the effect of fine aggregate may be useful for normal concrete using sea sand when an appropriate value of the modulus for coarse aggregate is provided. To be applicable to mortars other than those used here, the most significant remaining parameter is the volume fraction of sand which must be taken into consideration.

5.4. Prediction of the Tensile Modulus of Concrete by the Composite Model. By combining (7) with the composite

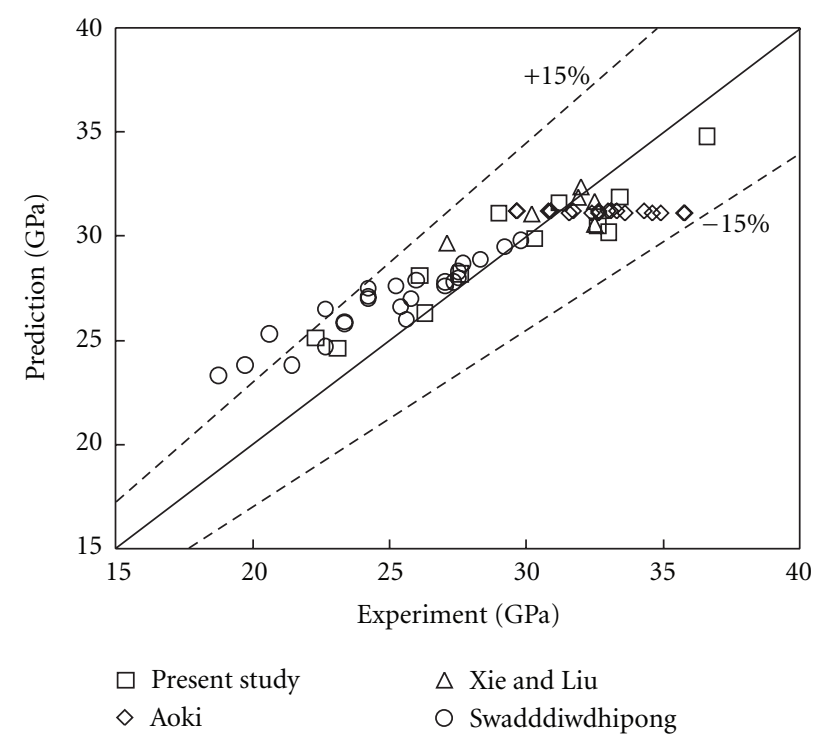

FIgURE 16: Comparison of experiments and predictions.

model (Figure 6), the age-dependent tensile moduli of concrete can be estimated from its mixture proportions (i.e., volume fraction of constituents) and the aggregate modulus. Figure 16 presents a comparison between the model predictions and the experimental data from this study as well as those from previous investigations [2, 4, 7]. Herein, these predicted data were obtained with the assumption that the aggregate properties in other studies are equal to the values employed in this study, because the modulus of coarse aggregate used is not reported in the previous investigations. The figure shows that the proposed method can predict the tensile modulus of concrete, with reasonable accuracy, solely based on the mixture proportions.

Figure 17(a) describes characteristics of tensile moduli of concrete with $W / C=55 \%$ and coarse aggregates of different volume fractions. The vertical axis in the graph presents the tensile Young's moduli ratio of concrete to coarse aggregate. Herein, the model results are obtained from the assumptions shown in Table 5. The figure demonstrates that the tensile modulus of concrete increases with increasing the volume of coarse aggregates since the aggregates have a higher Young's modulus than the mortars. It is also noted that tensile moduli of concrete having more coarse aggregates (i.e., larger vol. fractions) than the solid volume content of coarse aggregates [17] are unavailable. Figure 17(b) presents a similar set of curves corresponding to concrete with $W / C=30 \%$. Both figures describe that the tensile modulus of concrete develops rapidly at early age and gradually plateaus at later ages. 
TABle 5: Conditions for simulation of tensile Young's modulus.

\begin{tabular}{lc}
\hline Composite model & See Figure 6 \\
Elements & $80 \times 80$ \\
Air content & $4.5 \%$ \\
Tensile Young's modulus of mortar & see $(7)$ \\
Tensile Young's modulus of coarse aggregate & $36 \mathrm{GPa}$ \\
Solid volume content of coarse aggregate & $60 \%$ \\
Tensile Young's modulus of concrete & Average of 10 \\
& simulations \\
\hline
\end{tabular}

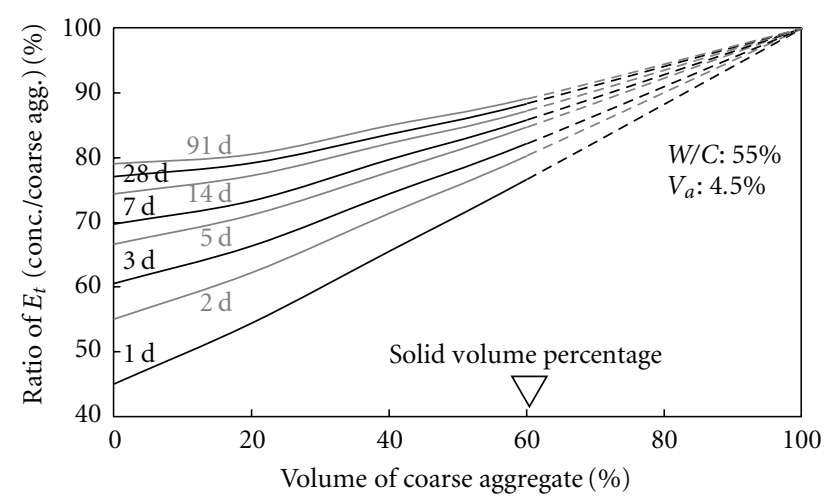

(a)

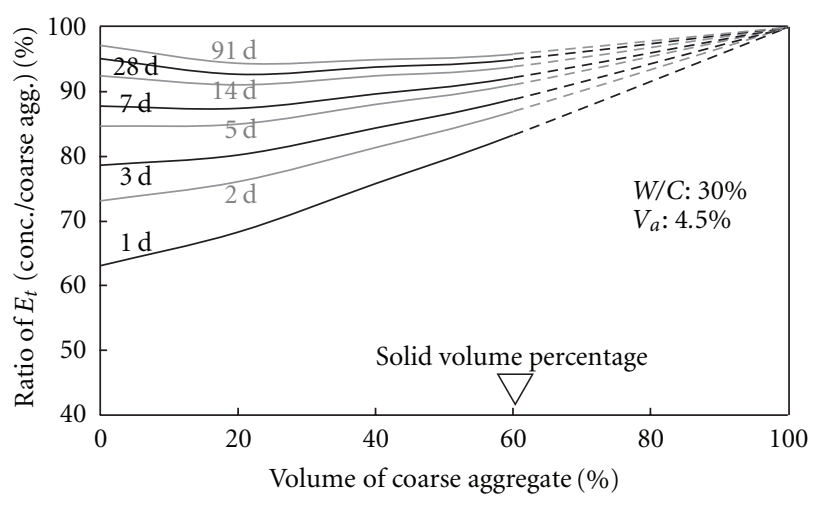

(b)

FIgURE 17: Prediction results for tensile Young's modulus of concrete: (a) $W / C=55 \%$ and (b) $W / C=30 \%$.

\section{Conclusions}

This paper describes the experimental measurement of tensile Young's modulus of concrete at early age using a direct tension setup. Moreover, a predictive composite model was developed to estimate the age-dependent tensile modulus of concrete using the volume fractions and properties of the constituents. The main conclusions are summarized as follows.

(1) The tensile stress-strain response of concrete was observed to be very linear even at early ages (e.g., 1 day old). The residual strains after repeated loading of specimens up to strains of $60 \times 10^{-6}$ were negligible. The tensile Young's modulus obtained from the stress-strain response develops according to the water-cement ratio and the age of concrete.

(2) The tensile modulus of concrete is approximately 1.0-1.3-times larger than its compressive modulus within the material's first week of age. As such, estimation of the tensile modulus based on empirical correlations with the compressive strength of concrete can be inaccurate.

(3) The age-dependent tensile moduli of concrete could be predicted appropriately by the proposed composite model as long as the volume fractions of coarse aggregates, mortar, and air, and the modulus of aggregates are known. In comparison with the experimental results, the model predictions showed accuracy better than $\pm 15 \%$.

\section{References}

[1] A. M. Neville, Properties of Concrete: Fourth and Final Edition, Pearson/Prentice Hall, 1995.

[2] Y. Aoki, K. Shimano, D. Iijima, and Y. Hirano, "Examination on simple uniaxial tensile test of concrete," Proceedings of the Japan Concrete Institute, vol. 29, no. 1, pp. 531-536, 2007 (Japanese).

[3] Architectural Institute of Japan, Recommendations of Practice of Crack Control in Reinforced Concrete Buildings-Design and Construction, Architectural Institute of Japan, 2006.

[4] N. Xie and W. Liu, "Determining tensile properties of mass concrete by direct tensile test," ACI Materials Journal, vol. 86, no. 3, pp. 214-219, 1989.

[5] F. A. Oluokun, E. G. Burdette, and J. H. Deatherage, "Elastic modulus, Poisson's ratio, and compressive strength relationships at early ages," ACI Materials Journal, vol. 88, no. 1, pp. 3-10, 1991.

[6] S. Hagihara, S. Nakamura, Y. Masuda, and M. Kono, "Experimental study on mechanical properties and creep behavior of high-strength concrete in early age," Concrete Research and Technology, vol. 11, no. 1, pp. 39-50, 2000 (Japanese).

[7] S. Swaddiwudhipong, H. R. Lu, and T. H. Wee, "Direct tension test and tensile strain capacity of concrete at early age," Cement and Concrete Research, vol. 33, no. 12, pp. 2077-2084, 2003.

[8] B. Bissonnette, M. Pigeon, and A. M. Vaysburd, "Tensile creep of concrete: study of its sensitivity to basic parameters," $A C I$ Materials Journal, vol. 104, no. 4, pp. 360-368, 2007.

[9] I. Yoshitake, Y. Ishikawa, H. Kawano, and Y. Mimura, "On the Tensile Young's Moduli of early age concrete," Journal of Materials, Concrete Structures and Pavements, vol. 63, no. 4, pp. 677-688, 2007 (Japanese).

[10] T. J. Hirsh, "Modulus of elasticity of concrete affected by elastic moduli of cement paste matrix and aggregate," ACI Journal, vol. 59, no. 3, pp. 427-452, 1962.

[11] U. J. Counto, "The effect of the elastic modulus of the aggregate on the elastic modulus, creep and creep recovery of concrete," Magazine of Concrete Research, vol. 16, pp. 129-138, 1964.

[12] Z. Hashin, "The elastic moduli of heterogeneous materials," Journal of Applied Mechanics, ASME, vol. 29, no. 1, pp. 143150, 1962.

[13] H. Mihashi and J. P. D. B. Leite, "State-of-the-art report on control of cracking in early age concrete," Journal of Advanced Concrete Technology, vol. 2, no. 2, pp. 141-154, 2004. 
[14] F. P. Zhou, F. D. Lydon, and B. I. G. Barr, "Effect of coarse aggregate on elastic modulus and compressive strength of high performance concrete," Cement and Concrete Research, vol. 25, no. 1, pp. 177-186, 1995.

[15] I. B. Topçu, "Alternative estimation of the modulus of elasticity for dam concrete," Cement and Concrete Research, vol. 35, no. 11, pp. 2199-2202, 2005.

[16] L. M. Goral, "Empirical time-strength relations of concrete," ACI Journal, vol. 53, pp. 215-224, 1956.

[17] JIS A 1104, "Methods of Test for Bulk Density of Aggregates and Solid Content in Aggregates," Japan Industrial Standards Committee, 2006. 

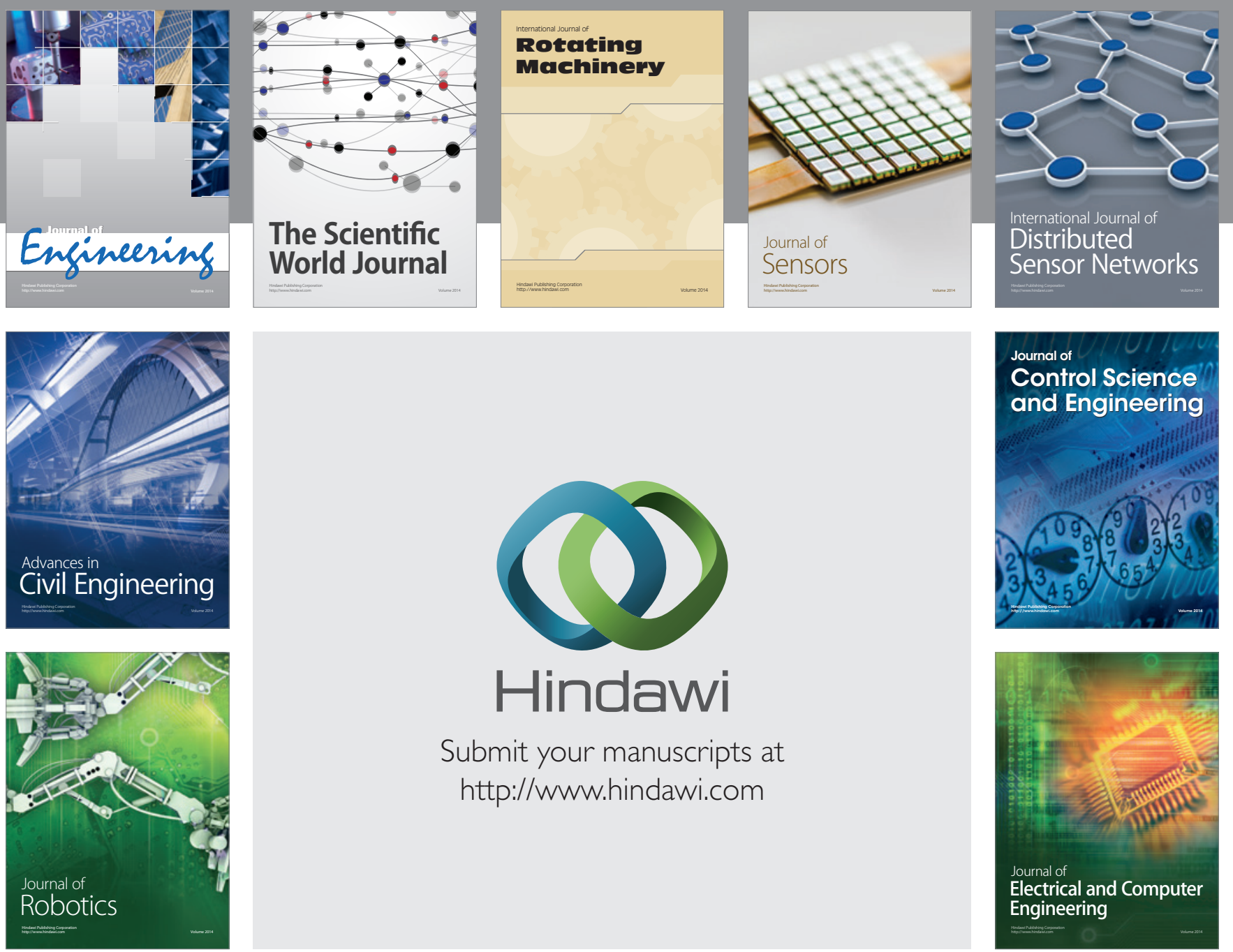

Submit your manuscripts at

http://www.hindawi.com
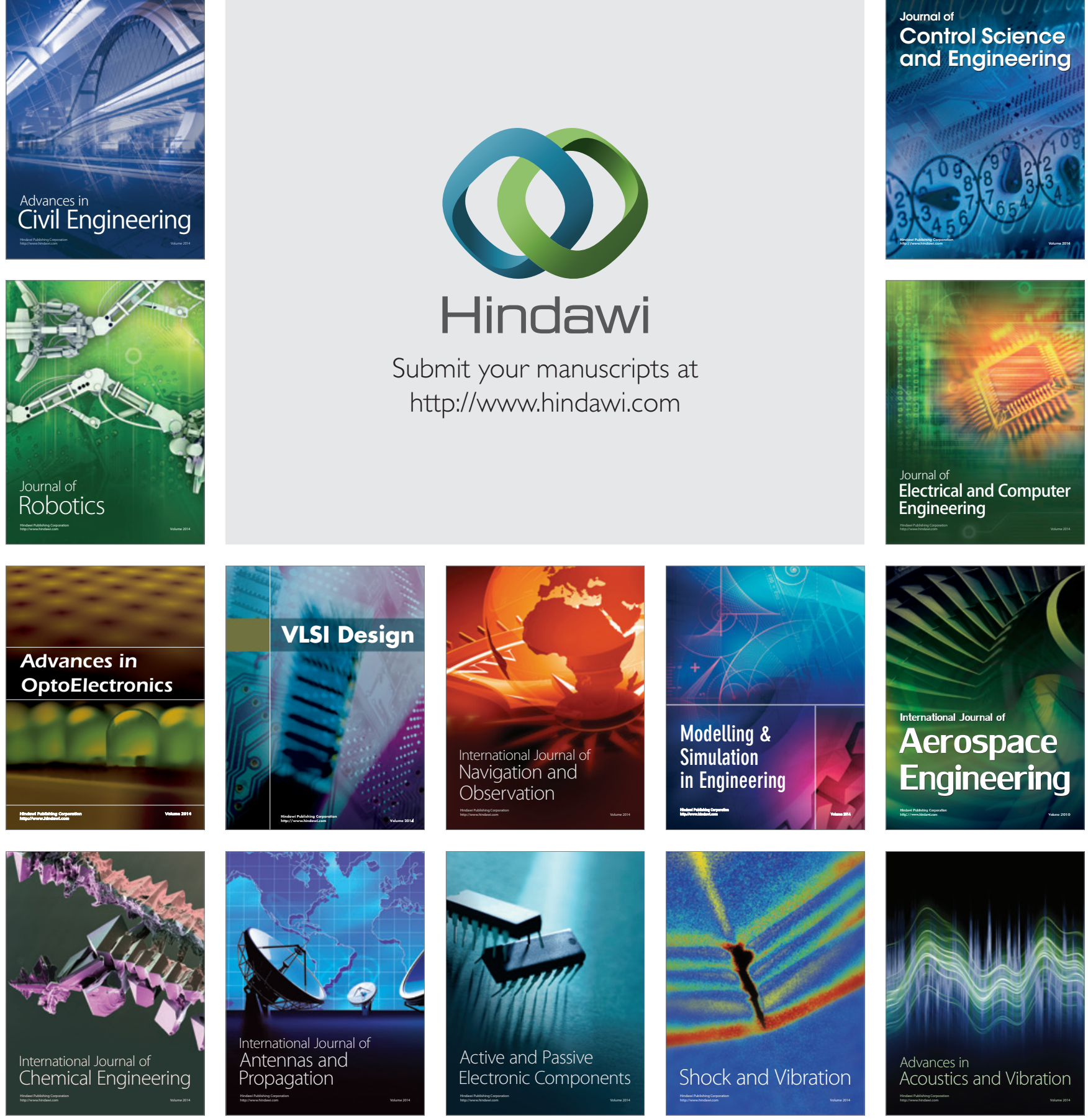